\title{
Hansen's Disease: differences in clinical presentation among Latin American and South East Asian born patients identified in Los Angeles County, California (1995-2016)
}

\author{
Curtis Croker MPH ${ }^{\mathrm{a}}$, Jeffrey Phommasith $\mathrm{PHN}^{\mathrm{b}}$, \\ Robert Jerskey OT ${ }^{\mathrm{b}}$, Amy Marutani MPH ${ }^{\mathrm{a}} \&$ Maria T. Ochoa MD ${ }^{\mathrm{b}}$ \\ aAcute Communicable Disease Control Program, Los Angeles County \\ Department of Public Health, USA \\ ${ }^{\mathrm{b}}$ Hansen's Disease Clinic, Los Angeles County University of Southern \\ California Medical Center, USA
}

Submitted 13 July 2020; Accepted 10 August 2020

\begin{abstract}
Summary
Background: Hansen's Disease (HD, or Leprosy) is a mycobacterial infection associated with severe nerve damage and physical disfigurement, primarily affecting economically disadvantaged persons. Increased morbidity occurs when patients experience an immunological reaction to this infection prior to, during, or after HD treatment. Our objective was to identify HD patients at risk for such reactions.

Methodology: We performed a multivariate retrospective case-control analysis of HD patient risk for reaction (types 1 and 2) among patients reported in Los Angeles County (LAC) (1995-2016). Risk factors included age, gender, report year, birth place, and bacillary classification (paucibacillary vs. multibacillary).

Findings: Most of the $78 \mathrm{LAC}$ HD patients identified for this study were male (78.2\%, $61)$, born in Latin America $(48.7 \%, 38)$ or South East Asia (SE Asia) $(41.0 \%, 32)$, classified as multibacillary $(88.5 \%, 69)$, with a median age of 43.5 years (range $18-82$ years). Sixty-two HD patients (79.5\%) experienced a reaction type: 34 experienced type $1(43.6 \%), 34$ experienced type $2(43.6 \%), 6$ experienced multiple types $(7.7 \%)$. SE Asian born patients were more likely to experience a type 1 reaction $(59.4 \%, \mathrm{aOR}=$ 3.0, CI: 1.2-7.7), whereas Latin American born patients were more likely to experience a type 2 reaction $(68.4 \%, \mathrm{aOR}=11.1, \mathrm{CI}: 3.5-35.1)$.

Conclusion: The risk of reaction types among LAC HD patients appears to be correlated with the patient's birth place, where their exposure likely occurred. Explanations for these differences include different mycobacterial variants circulating geographically, different immune responses of racial-ethnic groups to HD, and genetic associations.

Author Summary: Hansen's Disease is rare in Los Angeles County and primarily occurs among persons who acquired the infection outside of the US. The findings of
\end{abstract}

Correspondence to: Curtis Croker, Acute Communicable Disease Control, Los Angeles County Department of Public Health, 313 N. Figueroa St, 90012, USA. Tel.: 909-472-8388 (e-mail: ccroker@ph.lacounty.gov) 
this 22-year study of 78 Hansen's patients suggest that the clinical progression of this disease differs by the global region of exposure. Latin American born patients with Hansen's disease had eleven times the odds of developing a type 2 reaction, which is associated with severe long-term disability, than patients born in SE Asia. Possible explanations for this result include: (1) variations of the mycobacterial strain across the globe or, (2) variations in immunological responses of racial/ethnic groups to this mycobacterium. Both explanations may be the result of this agent being introduced into the Americans much more recently than in Asia. Clinicians should consider a patient's race/ethnicity background when developing a Hansen's Disease treatment plan.

Keywords: Leprosy, community stigma, paucibacillary Leprosy, case detection, global Leprosy situation

\section{Introduction}

An estimated 200,000 new HD patients are identified globally every year according to the World Health Organization (WHO), with about 150 of those patients identified in the United States according to the Centers for Disease Control. ${ }^{1-3}$ The causative agent (Mycobacterium leprae and $M$. lepromatosis $^{4}$ ) primarily affects the peripheral nerves and skin. ${ }^{5-8}$ Early detection and treatment of this infection and the immunological reactions that can occur are crucial in preventing permanent loss of sensation, motor function imparement, ocular morbidity and disfigurement. Determining the exposure for a HD patient is often difficult due to the potentially long incubation time for this slow growing mycobacterium (months to many years) and the long-term exposure needed to transfer sufficient organisms. ${ }^{5-8}$ Certain armadillos harbor the causative mycobacteria and may be a source of infection for some cases. ${ }^{7,9,10}$ Although person-to-person transmission of HD is rare within the U.S., it is the most common method of transmission globally. ${ }^{11,12}$ Once the proper antibiotic therapy is initiated, HD patients are rendered non-infectious. ${ }^{3}$ All LAC HD patients are reportable to the LAC Public Health Department (LACDPH) for investigation and treatment compliance monitoring. HD patient family members are referred to the HD specialty clinic at the LAC University of Southern California Medical Center for evaluation.

Immunological HD reactions (types $1,2,3$ ) are the leading cause of disability in patients with HD and are the result of the patient's immunological inflamatory response to the HD mycobacterial antigens. ${ }^{13-20}$ Up to $50 \%$ of all HD patients experience at least one of these reactions which may occur before, during, or after treatment. However, most patients experiencing a reaction usually do so within the first year of multidrug therapy (MDT) initiation. ${ }^{13,16}$ Immunosuppressive therapies are required, sometimes for many years, to treat these reactive episodes.

Type 1 reaction, also referred to as reversal reaction, is a delayed-type hypersensitivity reaction, resulting from increased cell-mediated immunity to the mycobacterial antigen. ${ }^{13-17}$ HD patients at increased risk for this reaction include those with facial lesions, the involvement of three or more body areas and pregnancy. Up to one-third of all HD patients develop a type 1 reaction, but the frequency of this reaction varies considerably in the literature. ${ }^{13-17}$ Type 2 reaction, also referred to as erythema nodosum leprosum, is considered a systemic disease accompanied by fever, joint pain and painful skin leassion. ${ }^{13-15,18,19}$ Type two reactions are believed to be the result of an immune complex deposition. Up to one-third of all HD patients develop a type 2 reaction, with the frequency of this reaction also varying considerably in 
the literature. ${ }^{13-15,18,19}$ A recent study of California HD patients identified a type 2 reaction prevalence of $74.1 \% .{ }^{19} \mathrm{MB}$ HD patients are at increased risk for this reaction and associated with higher morbidity. ${ }^{18,20}$ Type 3 reaction, also referred to as Lucio's phenomenon , is the rarest and the most severe of these reaction types. ${ }^{21-23}$ It is primarily seen in patients of Mexican and Central American ancestry and associated with severe necrosis, vasculitis and occasional mortality.

Earlier HD studies have shown that the prevalence of these immunological reactions among HD patients varies considerably by global region, but it is difficult to establish true regional variation due to the differing study designs (case definitions, follow-up time, analytical methodology) and retrospective nature of most HD studies. Complicating matters further are the differing classification schemes by global region that are employed to describe the clinic presentation of HD patients, starting with the 1953 Madrid classification, followed by the 1966 Ridley-Jopling classification ${ }^{25}$ and 1982 WHO classification updated in $1998 .^{26}$ The objective of this study was to document LAC HD patient trends and risk factors associated with HD reactions for patients diagnosed at a single specialty clinic.

\section{Methods}

An existing dataset containing information on all HD patients reported to LAC DPH from 1970 to 2019 was utilized to review LAC HD trends over the last 50 years. The following variables were utilized from this database; (1) age (2) gender (3) reported year (4) birth country and (5) Ridley-Jopling five-category HD classification (1966). The Ridley-Jopling HD classification (TT, TB, BB, BL, LL) was converted to the 1982 WHO two-point HD classification (paucibacillary or $\mathrm{PB}$, multibacillary or $\mathrm{MB}$ ) in the following manner ( $\mathrm{PB}=$ $\mathrm{TT}$ or $\mathrm{BT}$, and $\mathrm{MB}=\mathrm{BB}$ or $\mathrm{BL}$ or $\mathrm{LL}$ ). For the trend analysis, HD patient age was aggregated into three groups (18-34, 35-54, 55-84 years), birth regions into three groups (SE Asian, Latin American, or other region) and reporting year into five groups (1970's, 1980's, 1990's, 2000's, 2010 's). These categories were chosen to provide adequate numbers for a robust representation of each category. Age group, birth region, gender and HD classification were calculated for each reporting decade and trends by decade were constructed. Crude HD incident rates were calculated by decade using the U.S. census data files for LAC population and utilizing a midpoint year for each decade.

For the analysis of risk factors for HD patient reaction types, we created a more detailed dataset of patients reported from 1995-2016 though review of HD patient medical records. Three study groups were created for the study of risks of any reaction (types 1, 2 or 3), type 1 reaction, and type 2 reaction. A case of any reaction was defined as any patient having a type 1,2 , or 3 reaction and a control was defined as a patient not experiencing a reaction. A type 1 reaction case was defined as any patient identified with this specific reaction and a control was defined as any HD patient lacking this reaction but could include patients having other reaction types. A type 2 reaction case was defined as a patient identified with this reaction and a control was defined as any patient lacking this specific reaction but could include patients having other reaction types. For these analyses, age was aggregated into three groups (18-34, 35-54, 55-84 years), birth countries into three groups (SE Asian, Latin American, or other region) and year reported into three groups (1995-1999, 2000-2009, 2010-16). Patient records were reviewed through 2019 so that each patient had a minimum of 3 years of follow-up for a reactive episode to be identified. The prevalence of any reaction and specific reaction types 1 and 2 for age groups, gender, reporting year groups, and birth region were calculated. Because 
of the rarity of type 3 reactions, only frequencies were calculated with limited demographic stratification.

A case-control univariate (chi-squared test) and multivariate analysis (Wald Chi-Square test) was utilized to assess the association of these groups with reaction types. Because age, gender, year reported, and birth region may be potential risk factors for these reactions, we controlled for these variables in the multivariate analysis. The average follow-up time was calculated for the study group and compared by gender, age group, and birth region to evaluate any bias that may be introduced by differences in patient follow-up time.

Microsoft Access version 1906 was utilized for data storage and SAS version 9.4 software was utilized for the study analysis.

\section{Results I-Trends in LAC HD Patients (1970-2019, $N=\mathbf{2 4 0})$}

There were 240 HD patients reported in LAC over the last 50 years (1970 to 2019). Patients were more likely to be male $(67.1 \%)$ than female (32.9\%) and most were foreign-born $(99.2 \%)$. Patient birth regions included Latin American (61.7\%), SE Asia (29.6\%), and other birth regions $(8.8 \%)$. Only two patients $(0.8 \%)$ were born in the U.S. (both from Texas) and were reported in the first decade of the study. The average patient age was 46.3 years (range: 18 to 82 , median 43.5 years). Most patients were identified as MB (90.4\%).

The number of LAC HD patients and rate increased from the decade of the 1970's $(n=50)$ to the 1980 's $(n=72)$, corresponding to an increase in the proportion of male patients $(48.0 \%$ to $63.4 \%$ ) and those born in SE Asia (8.0\% to 31.9\%) (Figure 1). This increase also corresponded to a decrease in the proportion of younger patients age $15-34$ years $(62.0 \%$ to $45.1 \%)$. Since the 1980 's the number of HD patients and rate have decreased over the preceding three decades to 24 cases in the last decade (2010's) accompanied by a continued increase in the proportion of male patients, a decrease in the proportion of younger patients (age 15-34), and Latin American born patients. The rate in the last decade surveyed was 0.24 per million persons. The average age of a patient increased by 12.1 years from the 1970's to the 2010's (31.7 to 43.8 years). The proportion of MB patients decreased slightly from the 1970's to the 2010's $(94 \%$ to $87.5 \%)$.

\section{Results II-Analysis of Risk Factors Associated with HD Reaction ( $N=78,1995-2016)$}

Seventy-eight HD patients reported in LAC from 1995-2016 were utilized for the analysis of HD reactions. The crude rate of HD in LAC for the study period was 0.36 per million ((78/22)/9.8 million residents). These patients were mostly male (78.2\%), born in Latin America (48.7\%) or SE Asia (41.0\%) or other region (10.3\%) with an average age of 46.3 years (range 18-82 years, median 46.3 years). Male patients were slightly older than female patients (average age: 53.5 vs. 44.3 years, $p=0.03$ ). Sixty-nine patients were classified as MB (88.5\%), which was more common among Latin American born (100\%) than SE Asian born patients $(81.3 \%)$. No other categorical differences were observed. The average patient followup time was 14.7 years (range: 3-24 year). A shorter average follow-up time was observed for patients in the later part of the study (8.9 years, 2005-2017) compared to the earlier part of the study (21.5 years, 1994-2000, $p<0.01$ ), but no differences in follow-up time by age, gender, race/ethnicity or HD classification were observed. There was only one instance where two patients shared the same LAC address. Both patients were born in an HD endemic area, making it difficult to determine if transmission occurred within this LAC household or was 

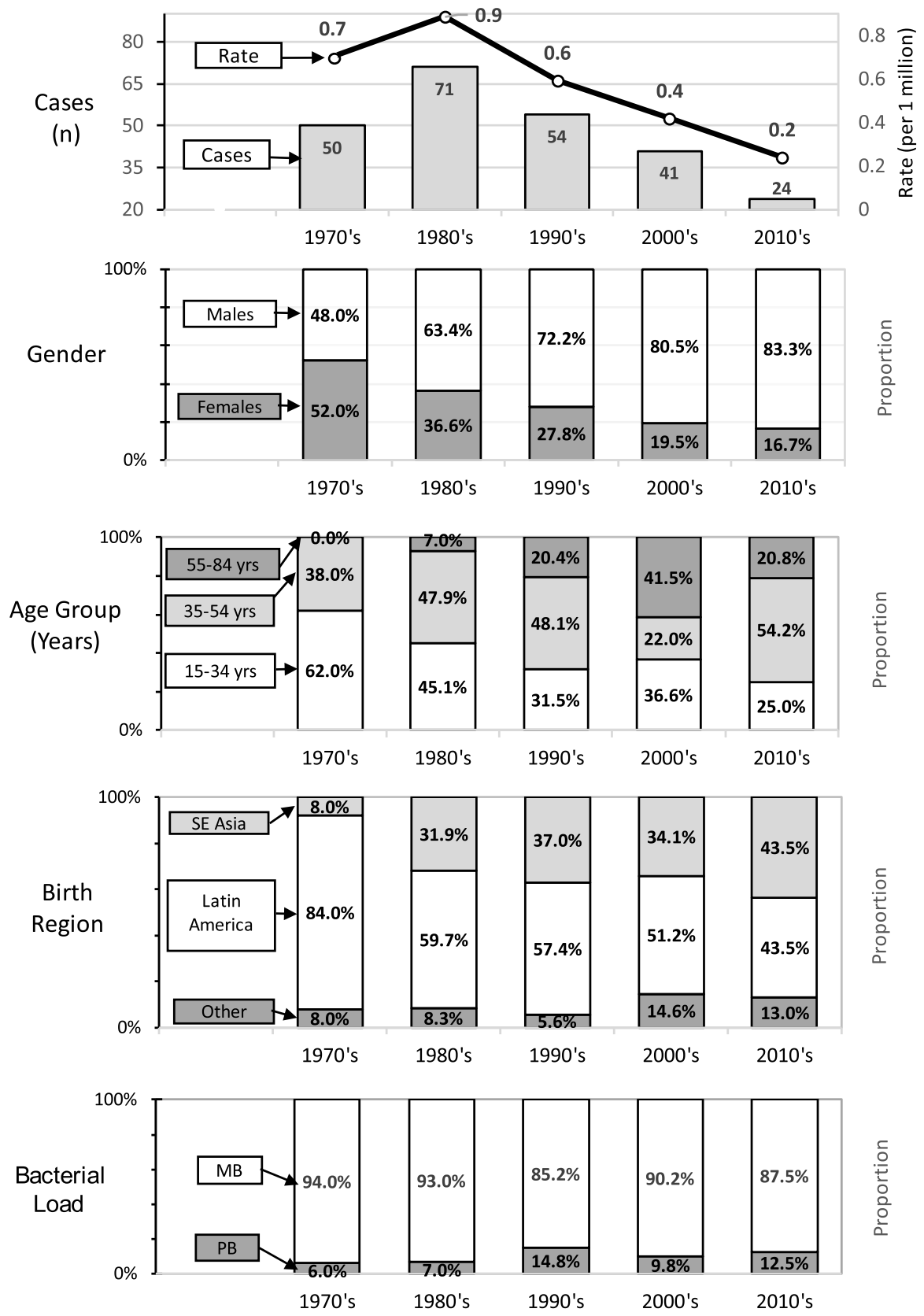

Figure 1 Hansen's Disease Reported in Los Angeles County from 1970-2019 $(N=240)$ by Gender, Age Group, Birth Region and HD Classification.

acquired in their birth country. There was no other evidence to suggest that the exposure for any of these HD patients occurred in LAC. 
Table 1. Risk of Type 1 Reactions Among Hansen's Disease Patients Los Angeles County, 1995 to $2016(N=78)$

\begin{tabular}{|c|c|c|c|c|c|c|c|c|c|c|}
\hline \multirow[b]{3}{*}{ Overall } & \multirow[b]{3}{*}{$\begin{array}{c}\text { Total } \\
78\end{array}$} & \multirow[b]{3}{*}{$\begin{array}{c}\% \\
100.0 \%\end{array}$} & \multirow[b]{3}{*}{$\begin{array}{c}n \\
34\end{array}$} & \multirow[b]{3}{*}{$\begin{array}{c}\% \\
43.6 \%\end{array}$} & \multicolumn{4}{|c|}{$\begin{array}{l}\text { Type } 1 \text { Reaction } \\
\text { Analysis }\end{array}$} & & \multirow{3}{*}{ UCI } \\
\hline & & & & & \multicolumn{3}{|c|}{ Univariate } & Multivariate & & \\
\hline & & & & & OR & LCI & $\mathrm{UCI}$ & OR & LCI & \\
\hline \multicolumn{11}{|l|}{ Year Group* } \\
\hline 1995-1999 & 21 & $26.9 \%$ & 9 & $42.9 \%$ & 1.0 & 0.3 & 2.6 & 1.0 & 0.4 & 2.9 \\
\hline 2000-2009 & 26 & $33.3 \%$ & 10 & $38.5 \%$ & 0.7 & 0.3 & 1.9 & 0.8 & 0.3 & 2.2 \\
\hline 2010-2016 & 31 & $39.7 \%$ & 15 & $48.4 \%$ & 1.4 & 0.6 & 3.4 & 1.2 & 0.5 & 3.2 \\
\hline \multicolumn{11}{|l|}{ Gender } \\
\hline Male & 61 & $78.2 \%$ & 26 & $42.6 \%$ & 0.8 & 0.3 & 2.5 & 0.7 & 0.2 & 2.2 \\
\hline Female & 17 & $21.8 \%$ & 8 & $47.1 \%$ & 1.2 & 0.4 & 3.5 & 1.4 & 0.4 & 4.4 \\
\hline \multicolumn{11}{|l|}{ Age Group* } \\
\hline $18-34$ years & 21 & $26.9 \%$ & 9 & $42.9 \%$ & 1.0 & 0.4 & 2.6 & 1.1 & 0.4 & 3 \\
\hline $35-54$ years & 31 & $39.7 \%$ & 13 & $41.9 \%$ & 0.9 & 0.4 & 2.2 & 1.0 & 0.4 & 2.5 \\
\hline $55-84$ years & 26 & $33.3 \%$ & 12 & $46.2 \%$ & 1.2 & 0.5 & 3.0 & 1.0 & 0.4 & 2.7 \\
\hline \multicolumn{11}{|l|}{ Birth Region } \\
\hline Latin America & 38 & $48.7 \%$ & 11 & $28.9 \%$ & 0.3 & 0.1 & 0.8 & 0.3 & 0.1 & 0.8 \\
\hline SE Asian & 32 & $41.0 \%$ & 19 & $59.4 \%$ & 3.0 & 1.2 & 7.7 & 3.0 & 1.2 & 7.7 \\
\hline Other & 8 & $10.3 \%$ & 4 & $50.0 \%$ & 1.3 & 0.3 & 5.8 & 1.3 & 0.3 & 6.1 \\
\hline \multicolumn{11}{|c|}{ Among Latin American and SE Asian Only, $n=70$} \\
\hline Latin America & 38 & $54.3 \%$ & 11 & $15.7 \%$ & & Referenc & & & ferenc & \\
\hline SE Asian & 32 & $45.7 \%$ & 19 & $27.1 \%$ & 3.6 & 0.3 & 9.7 & 4.7 & 1.6 & 13.7 \\
\hline \multicolumn{11}{|l|}{ HD Classification* } \\
\hline Multibacillary & 69 & $88.5 \%$ & 31 & $44.9 \%$ & 1.6 & 0.4 & 7.1 & 3.8 & 0.8 & 18.9 \\
\hline
\end{tabular}

Sixty-three HD patients were identified with a type 1, 2 or 3 reaction (80. 7\%), with some patients having multiple reaction types $(9,11.5 \%)$. The prevalence of reactions in each category were as follows: MB patients (85.1\%), Age: 18-34 years (90.5\%), 35-54 years $(77.4 \%)$, 55-84 years $(69.2 \%)$; Gender: male $(80.3 \%)$, female $(70.6 \%)$; Report Year: 1995-1999 (76.2\%), 2000-2009 (76.9\%), 2010-2016 (80.7\%); Birth Region: Latin America (84.2\%), SE Asia (75.0\%), other region(62.5\%). Sixty-two HD patients (79.5\%) experienced a type 1 or 2 reaction and were utilized as cases for the case-control risk analysis: type 1 (34, $43.6 \%)$, type $2(34,43.6 \%)$, and multiple types $(6,7.7 \%)$.

For the analysis of type 1 reactions, the 34 patients with this reaction were utilized as cases and 44 patients lacking this reaction were utilized as controls (controls included 31 patients with another reaction type, not type 1). The prevalence of this reaction was higher among SE Asia born patients $(59.4 \%)$ who were at increased risk for this reaction type $(\mathrm{aOR}=3.0$, CI 1.2-7.7, Table 1). The prevalence of a type 1 reaction was lower among Latin America born patients $(28.9 \%)$ who were at a decreased risk for this reaction $(\mathrm{aOR}=0.3$, CI 0.1-0.8). HD patients born in SE Asia had 4.7 times the odds (aOR) of having a type 1 reaction compared to their Latin American born counterparts (CI: 1.6-13.7). Age group, gender, reported year group, and HD classification were not associated with an increased risk of a type 1 reaction.

For the analysis of type 2 reactions, the 34 patients identified with this reaction were utilized as cases along with 44 controls (controls included 28 patients with other reaction type, not type 2). All HD patients experiencing this reaction were classified as multibacillary (100\%, Table 2). Latin American born patients had a higher frequency (68.4\%) and increased risk of a type 2 reaction $(\mathrm{aOR}=11.1, \mathrm{CI}: 3.5-35.1)$, while SE Asian born patients had a lower 


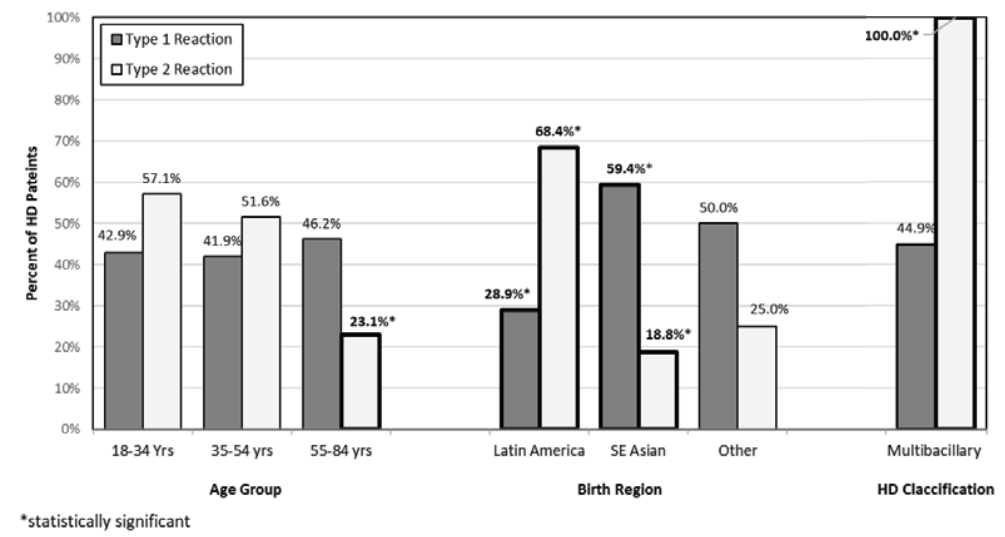

Figure 2 Prevalence of Types 1 and 2 Reaction Among Hansen's Disease Patients in Los Angeles County from 1995-2016 $(N=78)$ by age Group, Birth Region and HD Classification.

frequency (18.8\%) and decreased risk of this reaction (aOR $=0.1, \mathrm{CI}: 0.1-0.4)$. Among only Latin American and SE Asian born patients, Latin American born patients had 10.8 times higher odds (aOR) of having a type 2 reaction compared to their SE Asian born counterparts (CI: 3.2-36.0) $(n=70)$. Among only MB patients, Latin American born patients had 8.2 times higher odds (aOR) of having this reaction compared to their SE Asian born counterparts (CI: 2.4-27.9) $(n=64)$. Type 2 reactions were less common among patients age 55-84 years $(23.1 \%)$ who were at a reduced risk for this reaction $(\mathrm{aOR}=0.3, \mathrm{CI}$ : $0.1-0.9)$. Among only multibacillary HD patients, this age group remained at reduced risk for this reaction $(\mathrm{aOR}=$ 0.2 , CI: $0.1-0.8, n=69$ ). No association with type 2 reaction risk by gender or reported year group was identified. The analysis categories associated with Type 1 and Type 2 reactions (age group and birth region) are shown in Figure 2.

Type 3 reactions were identified among four LAC HD patients $(5.1 \%)$, all of which were Latin American born. Among only Latin American born patients, the frequency of type 3 reaction was $10.5 \%$. Three of these patients were also identified with a type 2 reaction $(75 \%)$. The age of these type 3 patients ranged from $28-55$ years. This reaction type was identified throughout the study period.

\section{Discussion}

Hansen's disease is rare in LAC and primarily affects residents born in SE Asia and Latin America where their respective exposures likely occurred. Over the last 50 years, our local health department (LACDPH) has received 240 HD patients reports, with patient demographics becoming increasingly male, older, of SE Asian descent and decreasing of Latin American descent over time. The LAC HD patient birth region trends may reflect the changing global distribution of the disease, the changing U.S. immigration patterns, or some combination of both. The overall decreasing trend in the number and rate of LAC HD patients mirrors what is observed nationally, as well as globally. ${ }^{1-3}$

The HD rate identified in this 22-year LAC study $(n=78)$ was lower than that reported elsewhere in the US and globally; however, LAC patients appear to present with a more severe form of the illness than in other regions. The LAC HD case rate (0.36 per million, 1995-2016) is slightly lower than that reported nationally (0.43 per million, 2009-2011) and significantly 
Table 2. Risk of Type 2 Reactions Among Hansen's Disease Patients Los Angeles County, 1995 to $2016(N=78)$

\begin{tabular}{|c|c|c|c|c|c|c|c|c|c|c|}
\hline \multirow[b]{3}{*}{ Overall } & \multirow[b]{3}{*}{$\begin{array}{c}\text { Total } \\
78\end{array}$} & \multirow[b]{3}{*}{$\begin{array}{l}\% \\
100.0 \%\end{array}$} & \multirow[b]{3}{*}{$\begin{array}{c}n \\
34\end{array}$} & \multirow[b]{3}{*}{$\begin{array}{c}\% \\
43.6 \%\end{array}$} & \multicolumn{5}{|c|}{$\begin{array}{l}\text { Type } 2 \text { Reaction } \\
\text { Analysis }\end{array}$} & \multirow{3}{*}{$\mathrm{UCI}$} \\
\hline & & & & & \multicolumn{3}{|c|}{ Univariate } & \multicolumn{2}{|c|}{ Multivariate } & \\
\hline & & & & & OR & LCI & UCI & OR & LCI & \\
\hline \multicolumn{11}{|l|}{ Year Group* } \\
\hline 1995-1999 & 21 & $26.9 \%$ & 7 & $33.3 \%$ & 0.6 & 0.2 & 1.6 & 0.5 & 0.2 & 1.6 \\
\hline 2000-2009 & 26 & $33.3 \%$ & 12 & $46.2 \%$ & 1.2 & 0.5 & 3.0 & 0.6 & 0.2 & 2.8 \\
\hline 2010-2016 & 31 & $39.7 \%$ & 15 & $48.4 \%$ & 1.4 & 0.6 & 3.4 & 3.3 & 0.9 & 10.8 \\
\hline \multicolumn{11}{|l|}{ Gender } \\
\hline Male & 61 & $78.2 \%$ & 28 & $45.9 \%$ & 1.6 & 0.5 & 4.7 & 1.3 & 0.4 & 5.0 \\
\hline Female & 17 & $21.8 \%$ & 6 & $35.3 \%$ & 0.6 & 0.2 & 2.0 & 0.8 & 0.2 & 2.8 \\
\hline \multicolumn{11}{|l|}{ Age Group* } \\
\hline $18-34$ years & 21 & $26.9 \%$ & 12 & $57.1 \%$ & 2.1 & 0.8 & 5.9 & 2.8 & 0.8 & 9.7 \\
\hline $35-54$ years & 31 & $39.7 \%$ & 16 & $51.6 \%$ & 1.6 & 0.7 & 4.3 & 1.4 & 0.5 & 3.9 \\
\hline $55-84$ years & 26 & $33.3 \%$ & 6 & $23.1 \%$ & 0.3 & 0.1 & 0.8 & 0.3 & 0.1 & 0.9 \\
\hline \multicolumn{11}{|l|}{ Among MB Only, $n=69$} \\
\hline $18-54$ years & 45 & $65.2 \%$ & 28 & $62.2 \%$ & \multicolumn{3}{|c|}{ Reference } & \multicolumn{3}{|c|}{ Reference } \\
\hline $55-84$ years & 24 & $34.8 \%$ & 6 & $25.0 \%$ & 0.2 & 0.1 & 0.6 & 0.2 & 0.1 & 0.6 \\
\hline \multicolumn{11}{|l|}{ Birth Region } \\
\hline Latin America & 38 & $48.7 \%$ & 26 & $68.4 \%$ & 8.7 & 3.1 & 24.4 & 11.1 & 3.5 & 35.1 \\
\hline SE Asian & 32 & $41.0 \%$ & 6 & $18.8 \%$ & 0.2 & 0.1 & 0.4 & 0.1 & 0.1 & 0.4 \\
\hline Other & 8 & $10.3 \%$ & 2 & $25.0 \%$ & 0.4 & 0.1 & 2.1 & 0.3 & 0.1 & 1.7 \\
\hline \multicolumn{11}{|c|}{ Among Latin American and SE Asian Only, $n=70$} \\
\hline Latin America & 38 & $54.3 \%$ & 26 & $68.4 \%$ & 9.4 & 3.1 & 29 & 10.8 & 3.2 & 36.0 \\
\hline SE Asian & 32 & $45.7 \%$ & 6 & $18.8 \%$ & \multicolumn{3}{|c|}{ Reference } & \multicolumn{3}{|c|}{ Reference } \\
\hline \multicolumn{11}{|c|}{ Among Latin American and SE Asian MB Only, $n=64$} \\
\hline Latin America & 38 & $59.4 \%$ & 26 & $68.4 \%$ & 7.2 & 2.3 & 23 & 8.2 & 2.4 & 27.9 \\
\hline SE Asian & 26 & $40.6 \%$ & 6 & $23.1 \%$ & \multicolumn{3}{|c|}{ Reference } & \multicolumn{3}{|c|}{ Reference } \\
\hline \multicolumn{11}{|l|}{ HD Classification* } \\
\hline Multibacillary & 69 & $88.5 \%$ & 34 & $100.0 \%$ & - & - & - & - & - & - \\
\hline
\end{tabular}

*at HD diagnosis

lower than that reported globally (30 per million, 2016). ${ }^{1-3}$ LAC HD patients account for only $2.4 \%$ of nationally reported HD patients over the study period (78/3227). ${ }^{1}$ The proportion LAC HD patients classified as MB $(88.5 \%)$ was higher than that reported nationally $(57.7 \%)$, as well as that reported in recent studies conducted in Latin America $(61 \%)^{14}$ and in Asia $(66 \%){ }^{13}$ This may indicate that $\mathrm{PB}$ patients are being under-diagnosed in our region. In addition, the reaction rate (type 1, 2 and 3 combined) identified among LAC HD patients (78.2\%) was also found to be higher than that generally reported in the literature (up to 50\%) ${ }^{13-15}$ and may be due, in part, to the larger proportion of MB patients in our study population who are at increased risk for these reactions. The longer follow-up time allowed in our study (average 14.7 years) compared to most other studies may have also contributed to higher rates of MB and reactions.

The type 1 reaction rate identified among LAC HD patients $(43.6 \%)$ was higher than that reported in the literature (up to 33\%). ${ }^{13-17}$ By birth region, SE Asian LAC HD patients had a type 1 reaction rate nearly twice the highest value reported in a recent HD study conducted in Asian $(29.0 \%) .{ }^{13}$ Latino-born LAC HD patients had a type 1 reaction rate (28.9\%) comparable to the highest value reported in the recent HD study conducted in Latin America (26.6\%). ${ }^{14}$ 
Age, gender and reporting year of our patients were not associated with increased risk of a type 1 reaction, which is consistent with findings reported in the literature. ${ }^{13-17}$

The type 2 reaction rate identified among LAC HD patients $(43.6 \%)$ was higher than that reported in the literature (up to 33\%). ${ }^{13-15,18-20}$ Latin American born LAC patients had a type 2 reaction rate $(68.4 \%)$ over twice the highest value reported in a recent HD study conducted in Latin America (31.3\%). ${ }^{14}$ The LAC HD type 2 reactions rate was also higher than the highest value reported in a recent article summarizing the findings of a number of HD studies conducted primarily in India and Brazil (15.4\%). ${ }^{18}$ SE Asian LAC HD patients had a reaction rate $(18.8 \%)$ that was over twice the highest value reported in recent study conducted in Asia $(7.6 \%) .{ }^{13}$

The type 3 reaction rate identified among all LAC HD patients $(5.1 \%)$ and among only Latin American born patients (10.5\%) were both lower than that reported in a recent study of HD patients conducted in Mexico (14.9\%). ${ }^{21}$ All LAC HD patients with a type 3 reaction were Latin American born, which is consistent with the literature. ${ }^{21-23}$

This study found Latin American born LAC HD patients to be at a higher risk for a type 2 reaction, whereas SE Asian patients were found to be at higher risk for a type 1 reaction. One explanation for these differences in reaction types and birth region include different mycobacterial variants circulating geographically. ${ }^{21,27}$ Studies have shown that more severe Hansen's disease appears in patients with a slight genetic variation in the mycobacterial make-up and associated with more frequent type 2 reactions. ${ }^{26}$ Another explanation is a possible difference in the patients' genetic make-up that predisposes patients for certain reaction types. ${ }^{28}$ Both explanations may be the result of the mycobacteria that causes HD being introduced into the Americas much more recently than in Asia. ${ }^{8}$ There may be other HD related or non-HD ralated comorbidities that could potentially impact the severity of disease and risk for reaction that need further study.

This study also identified LAC patients over the age of 54 years were at lower risk for a type 2 reaction than other age groups. Manandhar et al. found a similar age trend, with patients over the age of 45 years having a lower prevalence and reduced risk (16\% vs. 19\% overall, OR 0.69 , CI: $0.5-0.94) ;{ }^{20}$ however, most other studies do not identify a reduced reaction risk with increased age. ${ }^{18}$ This potential age association should to be researched further. LAC HD patient gender was not associated with type 2 reaction, which is consistent with that reported in the literature. ${ }^{18}$

The risk of acquiring HD in LAC appears extremely low, as evidenced the lack of household clustering of HD patients observed over the last 50 years $(N=240)$ and supported by the fact that nearly all patients were born in regions where the disease is endemic. Earlier studies of nationally reported HD patients suggest a much higher proportion of endemic HD patients $(10 \%)$, primarily occurring in Texas, Hawaii, Louisiana, and California. ${ }^{12}$ Details on individual endemic U.S. patients have been reported in New York, New Jersey, and Texas. ${ }^{12}$ The rarity of HD transmission in LAC is at least partly due to a combination of the low transmission rate for this disease, public health education and control activities, and proper assessment and treatment of patients by our specialty HD clinics. The results of this study will enable clinicians to better recognize HD patients at risk for these reactions and mitigate potential morbidity. Clinicians should consider a patient's race/ethnicity when developing a HD treatment plan.

This study is not without limitations. Identifying many of the dates of interest, such as date of illness onset and date of first reaction were difficult to assess for this chronic disease that is often misdiagnosed for months or years. This information may have better allowed us to substantiate the decrease in risk for type 2 reaction with increasing age identified here. 
Although a shorter average follow-up time was identified for patients diagnosed later in the study, we believe that any bias introduced was minimized by controlling for "reported year group". In addition, other reports suggest that HD patients experiencing a reaction do so during the first year of treatment, suggesting that the bias discussed here should be minimal. ${ }^{13,16}$ In addition, patients that relocated outside of LAC and patients who became deceased during the study period were not accounted for. Because most reactions were identified early in the treatment process, we believe the biasing effects of relocation and death to be minimal.

\section{Acknowledgments}

This project would not have been possible without the many staff at the Hansen's Disease Clinic at LAC-USC Medical Center and LAC DPH that have maintained the patient records and surveillance data. Special thanks to Dr. Bessie Hwang for supporting this research.

\section{References}

1 Nolen L, Haberling D, Scollard D, Truman R, Rodriguez-Lainz A et al. Incidence of Hansen's Disease — United States, 1994-2011. MMWR Morb Mortal Wkly Rep. 2014; 63(43): 969-972.

2 Report: A Summary of Hansen's Disease in the United States-2014. U.S. Department of Health and Human Services Health Resources and Services Administration National Hansen's Disease Program. Released 2015. https://www.hrsa.gov/sites/default/files/hansensdisease/pdfs/hansens2014report.pdf.

3 Guidelines for the Diagnosis, Treatment and Prevention of Leprosy. World Health Organization 2018 ISBN: 9789290226383.

4 Han XY, Silva FJ. On the age of Leprosy. PLOS Neglected Tropical Diseases, 2014; 8(2): e2544, https://doi.or g/10.1371/journal.pntd.0002544.

5 Gelber RH. Leprosy (Hansen's disease). In: Kasper DL, Braunwald E, Fauci AS, Hauser SL, Longo DL, Jameson JL (eds), Harrison's principles of internal medicine. 16th edn, New York, NY: McGraw-Hill, 2005; pp. 966-972.

6 Schreuder PAM, Noto S, Richardus JH. Epidemiologic trends of leprosy for the 21st century. Clinics in Dermatology, 2016; 34(1): 24-31, doi:10.1016/j.clindermatol.2015.11.001. PMID 26773620.

7 Scollard DM, Adams LB, Gillis TP, Krahenbuhl JL, Truman RW, Williams DL. The continuing challenges of leprosy. Clin Microbiol Rev, 2006; 19(2): 338-381.

8 Lastória JC, Abreu MA. Leprosy: review of the epidemiological, clinical, and etiopathogenic aspects - part 1. An Bras Dermatol, 2014; 89(2): 205-218, doi:10.1590/abd1806-4841.20142450.

9 Sharma R, Singh P, WJ Loughry . Zoonotic Leprosy in the Southeastern United States. Emerging Infectious Diseases, 2015; 21(12): -2134, 2127.

10 Truman RW, Singh P, Sharma R, Busso P, Rougemont J, Paniz-Mondolfi A, Kapopoulou A, Brisse S, Scollard DM, Gillis TP, Cole ST. Probable zoonotic leprosy in the southern United States. N Engl J Med, 2011; 364: $1626-1633$.

11 Sotiriou MC, Stryjewska BM, Hill C. Two Cases of Leprosy in Siblings Caused by Mycobacterium lepromatosis and Review of the Literature. American Journal of Tropical Medicine and Hygiene, 2016; 95(3): 522-527, doi:1 0.4269/ajtmh.16-0076, PMID 27402522.

12 Mastro TD, Redd SC, Breiman RF. Imported leprosy in the United States, 1978 through 1988: an epidemic without secondary transmission. American Journal of Public Health, 1992; 82(8): 1127-1130.

13 Balagon MV, Gelber RH, Abalos RM, Cellona RV. Reactions following completion of 1 and 2 year multidrug therapy (MDT). Am J Trop Med Hyg, 2010; 83(3): 637-644, doi:10.4269/ajtmh.2010.09-0586.

14 de Lima AS, Pinto KC, Bona MPS, Mattos SML, Hoffmann MP, Mulinari-Brenner FA, Ottoboni VCD. Leprosy in a University Hospital in a Southern State of Brazil. An Bras Dermatol, 2015; 90(5): 654-659.

15 Van Brakel WH, Khawas IB, Lucas SB. Reactions in leprosy: an epidemiological study of 386 patients in west Nepal. Leprosy Review, 1994; 65(3): 190-203.

16 Nery JA, Bernardes Filho F, Quintanilha J, Machado AM, Oliveira Sde S, Sales AM. Understanding the type 1 reactional state for early diagnosis and treatment: a way to avoid disability in leprosy. An Bras Dermatol, 2013; 88(5): 787-792, doi:10.1590/abd1806-4841.20132004.

17 Britton WJ. The management of leprosy reversal reactions. Lepr Rev, 1998; 69(3): 225-234.

18 Voorend CG, Post EB. A systematic review on the epidemiological data of erythema nodosum leprosum, a type 2 leprosy reaction. PLoS Negl Trop Dis, 2013; 7(10): e2440, doi:10.1371/journal.pntd.0002440. 
19 Chow M, Shue L, Sierro T, Tran K, Vaccaro S, Ochoa MT. Characterization and Outcomes of Patients With Hansen Disease Treated at the Los Angeles County Hospital [published online ahead of print, 2019 Aug 7]. JAMA Dermatol. 2019;155(10):1190-1192.

20 Manandhar R, LeMaster JW, Roche PW. Risk factors for erythema nodosum leprosum. Int J Lepr Other Mycobact Dis, 1999; 67(3): 270-278.

21 Han XY, Sizer KC, Velarde-Felix JS, Frias-Castro LO, Vargas-Ocampo F. The leprosy agents Mycobacterium lepromatosis and Mycobacterium leprae in Mexico. Int J Dermatol, 2012; 51: 952-959.

22 Lemus-Barrios GA, Hoyos-Pulgarín JA, Jimenez-Canizales CE. Lucio's phenomenon: A report of two cases and review of the literature. Case Reports in Internal Medicine, 2019; 6(2): 15-19.

23 Herath S, Navinan MR, Liyanage I et al. Lucio's phenomenon, an uncommon occurrence among leprosy patients in Sri Lanka. BMC Res Notes, 2015; 8: 672, doi:10.1186/s13104-015-1671-1.

24 Rea, TH and Jerskey, RS. Clinical and histologic variations among thirty patients with Lucio's phenomenon and pure and primitive diffuse lepromatosis (Latapi's lepromatosis) Int J Lepr Other Mycobact Dis 2005733169 188

25 Ridley DS, Jopling WH. Classification of leprosy according to immunity. A five-group system. Int J Lepr Other Mycobact Dis, 1966; 34(3): 255-273.

26 Gaschignard J, Grant AV, Thuc NV et al. Pauci- and multibacillary leprosy: Two distinct, genetically neglected diseases. PLoS Negl Trop Dis, 2016; 10(5): e0004345, doi:10.1371/journal.pntd.0004345.

27 Han XY, Jessurun J. Severe leprosy reactions due to Mycobacterium lepromatosis. Am J Med Sci, 2013; 345(1): 65-69, doi:10.1097/MAJ.0b013e31826af5fb.

28 Sousa ALM, Fava VM, Sampaio LH, Martelli CMT, Costa MB, Mira MT, Stefani MMA. Genetic and Immunological Evidence Implicates Interleukin 6 as a Susceptibility Gene for Leprosy Type 2 Reaction. The Journal of Infectious Diseases, 2012; 205(9): 1417-1424, https://doi.org/10.1093/infdis/jis208. 